\title{
O LEGADO DE NIELS BOHR
}

No ano de 1913, três manuscritos publicados no periódico Philosophical Magazine, de autoria do físico dinamarquês Niels Bohr, sob o título "On the Constitution of Atoms and Molecules", iriam estabelecer as sementes para a descrição quantitativa da estrutura eletrônica de átomos e moléculas. Estes trabalhos pioneiros de Bohr iriam impactar a Química em diversos aspectos fundamentais tais como a estrutura eletrônica dos elementos e sua relação com o conceito de valência, a relação entre periodicidade e configuração eletrônica, e nos princípios básicos da espectroscopia. Nada mais oportuno, portanto, do que a iniciativa da Química Nova em comemorar o centenário deste marco histórico da ciência e prestar uma homenagem e uma reflexão sobre o legado dos trabalhos de Niels Bohr. Em dois trabalhos deste número da QN, Carlos Alberto Lombardi Filgueiras e João Pedro Braga, conceituados pesquisadores brasileiros na área da Química que cultivam também grande interesse e curiosidade pelo desenvolvimento das ideias e teorias da Química, apresentam, com riqueza de detalhes, os aspectos históricos da contribuição científica de Bohr e o modelo físico idealizado por Bohr para descrever átomos e moléculas simples.

Uma série de resultados experimentais obtidos em diversos laboratórios de Física, principalmente na Europa, nos primórdios do século 20, causaram grande rebuliço científico e desencadearam a busca de modelos adequados para descrever a estrutura da matéria do ponto de vista microscópico. Os primeiros anos do século 20 vivenciaram também o surgimento do que se convenciona chamar a teoria quântica antiga formulada a partir da interpretação da radiação do corpo negro por Planck e da capacidade calorífica de sólidos por Einstein, e da introdução do conceito do fóton. Entretanto, coube a Bohr o grande mérito de propor um modelo teórico para a estrutura eletrônica de átomos, que baseado no modelo planetário introduzido por Rutherford em 1911, era capaz de explicar quantitativamente os espectros de emissão conhecidos na época, notadamente a série de Balmer do hidrogênio atômico, e daqueles que viriam ser observados em anos subsequentes.

A abordagem de Bohr partia de uma análise das condições necessárias para que um sistema de elétrons, girando numa órbita circular em torno de um núcleo fixo contendo cargas positivas, atingisse estabilidade mecânica. Bohr concluiu que as equações da mecânica clássica eram incapazes de prever a estabilidade mecânica destes sistemas, e lançou dois postulados quânticos importantes: i) a existência de estados estacionários associados com a quantização do momento angular orbital do elétron e a introdução do número quântico principal, e ii) um mecanismo discreto para emissão e absorção de radiação eletromagnética associado a transições entre dois estados estacionários (quânticos). Este mesmo critério de estabilidade mecânica foi utilizado no terceiro artigo de Bohr para descrever a estrutura eletrônica da molécula de hidrogênio, ilustrado no artigo de C. A. L. Filgueiras, J. P. Braga e N. H. T. Lemes nesta edição.

Ao contrário da maioria dos físicos da época, Niels Bohr se interessou em problemas mais diretamente relacionados com Química. Este interesse, frequentemente atribuído à grande amizade com o físico-químico húngaro George de Hevesy (ganhador do Prêmio Nobel de Química em 1943), resultou na extensão da teoria de Bohr não somente para átomos "hidrogênicos", mas também para átomos polieletrônicos. A abordagem de Bohr nesta fase consistiu em analisar o número de elétrons passíveis de serem acomodados em sucessivas orbitas. Apesar do sucesso na descrição do átomo de hidrogênio, o modelo de Bohr para átomos polieletrônicos, e a distribuição de elétrons em sucessivas orbitas, teve que ser ajustado de uma maneira um tanto arbitrária para corresponder a periodicidade e valência dos elementos químicos. Entretanto, as ideias de Bohr foram fundamentais para descrever a tabela periódica dos elementos químicos em função da configuração eletrônica dos átomos. A conexão dos trabalhos de Bohr com problemas mais relacionados com a Química também pode ser associada a sua interação frequente com grandes químicos contemporâneos da Dinamarca como Niels Janniksen Bjerrum, que iria aproveitar os conceitos espectroscópicos de Bohr para estudos pioneiros relacionados com vibrações e rotações moleculares, Johannes Nicolaus Brønsted e Jens Anton Christiansen.

Evidentemente, o modelo de Bohr teve o seu maior sucesso na interpretação de espectros atômicos. De um lado, a sua teoria foi capaz de reproduzir o valor exato da constante de Rydberg, e a sua teoria se mostrou muito útil para explicar fenômenos importantes como a variação do comprimento de onda dos raios- $\mathrm{X}$ emitidos pelos elementos químicos e sua relação com a carga nuclear corrigida pela blindagem do elétron interno da camada K (lei de Moseley). Este conceito de blindagem pelos elétrons internos foi também utilizado para interpretar os espectros atômicos dos metais alcalinos, e seria eventualmente incluído, algumas décadas depois, por Slater ao propor as chamadas funções monoeletrônicas de Slater utilizadas para cálculos simples de Química Quântica.

Apesar do sucesso do modelo de Bohr em reproduzir de maneira exata o espectro eletrônico do hidrogênio atômico e de átomos semelhantes, os químicos da época não foram ime- 
diatamente receptivos às ideias de Bohr. A ênfase no critério de estabilidade mecânica para descrever a estrutura eletrônica do átomo foi considerada muito complicada e pouco familiar para químicos acostumados com uma ciência puramente empírica. Este mesmo tipo de modelo para moléculas, baseado num modelo físico dinâmico, contrastava com o modelo estático introduzido por G. N. Lewis que privilegiava o compartilhamento de um par de elétrons para descrever a ligação química, conceito que iria eventualmente ser amplamente explorado por Pauling. Contudo, os resultados quantitativos dos primeiros cálculos moleculares de Bohr apresentaram grande novidade. Por exemplo, as primeiras experiências de Langmuir, ao redor de 1915, indicavam uma energia de ligação de $84 \mathrm{kcal} \mathrm{mol}^{-1}$ para a molécula de hidrogênio, valor não muito distante do valor previsto de $63 \mathrm{kcal} \mathrm{mol}^{-1}$ pela molécula de Bohr. A extensão deste modelo para moléculas poliatômicas não foi muito bem sucedida e a estabilidade prevista por Bohr para a molécula duvidosa de $\mathrm{H}_{3}$ só iria ser demonstrada espectroscopicamente por Herzberg em 1979 como sendo uma molécula de Rydberg, melhor representada como um íon $\mathrm{H}_{3}^{+}$ligado a um elétron num orbital muito distante.

Niels Bohr recebeu o Prêmio Nobel de Física em 1922, mas a sua contribuição para a Química pode ser avaliada pelo fato de ter sido proposto em duas ocasiões, 1920 e 1929, para o Prêmio Nobel de Química por químicos da Alemanha.

A partir da década de 1920, e com o declínio da antiga teoria quântica, Bohr começou a se afastar progressivamente de sua conexão com problemas de natureza química. Esta mudança de interesse teve muito a ver com a sua inclinação pela física teórica rigorosa e pelas inconsistências do modelo físico utilizado por Bohr que incorporava condições artificiais e de difícil justificativa para compatibilizar o conceito de es- tabilidade de órbitas progressivamente mais complexas com configurações eletrônicas.

Os trabalhos e ideias de Bohr tiveram outras contribuições marcantes na Química, como a derivação do momento magnético do elétron e a formulação da grandeza conhecida como magnéton de Bohr, fundamental em fenômenos de ressonância magnética e susceptibilidade magnética. Da mesma maneira, o princípio de correspondência ou a convergência do comportamento quântico para comportamento clássico no limite de números quânticos elevados representou um grande avanço na compreensão da junção suave entre fenômenos quânticos e fenômenos clássicos.

Niels Bohr teve uma atuação intensa durante a Segunda Guerra Mundial, atuando na Dinamarca, na Inglaterra e nos Estados Unidos. As suas preocupações humanísticas e a profundidade dos seus pensamentos estão retratadas em duas excelentes coleções de artigos publicadas em 1934 e 1957 sob os títulos de Atomic Theory and the Desciption of Nature e Atomic Physics and Human Knowledge. Nas palavras de cientistas que participaram desta época dourada da ciência, Niels Bohr foi um verdadeiro cavalheiro da ciência.

O legado histórico de Bohr é visível até hoje, e seu modelo planetário do átomo, embora totalmente superado, ainda é utilizado rotineiramente em livros textos de Química como uma introdução a uma visão física da estrutura dos átomos. Esta lembrança histórica e a contribuição à descrição atômica dos elementos químicos fazem parte do legado do Niels Bohr à Química.

José M. Riveros

Instituto de Química, Universidade de São Paulo CCNH, Universidade Federal do ABC 